\title{
The identification of eosinophilic gastroenteritis in prednisone-dependent eosinophilic bronchitis and asthma
}

\author{
Parameswaran Nair ${ }^{1 *}$, Sergei I Ochkur ${ }^{2}$, Cheryl Protheroe ${ }^{2}$, Elizabeth Simms ${ }^{1}$, Nancy A Lee ${ }^{2}$, James J Lee ${ }^{2}$
}

\begin{abstract}
This case reports the unique association of eosinophilic gastrointestinal disease with eosinophilic bronchitis, asthma and chronic rhinosinusitis and some features of lymphocytic hypereosinophilic syndrome, describes a diagnostic protocol for patients with asthma and persistent eosinophilic bronchitis, and suggests that the use of a novel EPXmAb provides a reliable method to identify eosinophilic inflammation.
\end{abstract}

\section{Introduction}

Eosinophilic gastrointestinal disease (EGID) is characterized by identification of abnormal eosinophilic infiltration on morphologic evaluation of gastrointestinal tissues obtained by biopsy or resection from patients with gastrointestinal complaints [1]. EGIDs are classified according to the site involved (i.e., esophageal, gastric, small intestinal, colonic, or multiple). Esophagus is increasingly being recognized as a site of involvement with eosinophils accumulating in the mucosal, muscular, serosal, diffuse, or transmural areas [2]. The diagnosis for eosinophilic esophagitis and other EGIDs is established after ruling out other causes of an eosinophilic disease, particularly atopy, parasitic infestations, vasculitis, and hypereosinophilic syndrome (HES) [3]. We report the association of eosinophilic gastroenteritis and eosinophilic bronchitis in a young patient with prednisone-dependent asthma and some features of lymphocytic hypereosinophilic syndrome and the sensitivity of a novel monoclonal antibody directed against eosinophil peroxidase $(E P X-m A b)$ [4] as an unambiguous means with which to detect both infiltrating tissue eosinophils and eosinophil degranulation in gastrointestinal tract biopsies. The patient provided written informed consent for publishing this manuscript.

\footnotetext{
* Correspondence: parames@mcmaster.ca

'Firestone Institute for Respiratory Health, St. Joseph's Healthcare and Department of Medicine, McMaster University, Hamilton, Ontario, Canada Full list of author information is available at the end of the article
}

\section{Case report}

A 23-year old woman was referred for assessment of cough, wheeze, shortness of breath, and chest tightness. She had frequent bloating, belching and loose stools. The symptoms had started two years prior to presentation with new onset sinus congestion, cough, wheeze and 40lb weight loss. Shortly after returning from a trip to Belize in the summer of 2008, her symptoms worsened and were associated with peripheral eosinophilia $\left(4.9 \times 10^{9} / \mathrm{L}\right)$ and diffuse peripheral pulmonary infiltrates. She had some features of chronic eosinophilic pneumonia; however, there was no clinical or laboratory evidence of vasculitis or hypereosinophilic syndrome (table 1). She did not have evidence of lymph node enlargement, organomegaly or skin lesions. Her FEV 1 and VC were $1.2 \mathrm{~L}$ (40\% predicted) and $2.4 \mathrm{~L}$ (65\% predicted) without any further improvement with a bronchodilator. Sputum was induced with hypertonic saline and processed as described by Pizzichini et al [5] and showed 80\% eosinophils. She was treated with high dose of prednisone, inhaled and nasal corticosteroids and had bilateral ethmoidectomy, sphenoidectomy and nasal polypectomy. Over the course of the next 12 months, her FEV improved to $2.1 \mathrm{~L}$ and her $\mathrm{PC}_{20}$ methacholine was 4.8 $\mathrm{mg} / \mathrm{ml}$ when her sputum eosinophils were $<1 \%$ on a maintenance dose of $12.5 \mathrm{mg}$ daily prednisone and fluticasone+salmeterol $(500+50 \mathrm{mcg})$ daily. In December 2009 , she presented with severe abdominal pain, vomiting, diarrhoea and weight loss. Her blood eosinophil had risen to 3.5 and her sputum showed $28 \%$ eosinophils. $\mathrm{FEV}_{1}$ had declined to $1.5 \mathrm{~L}$. Colonoscopy and gastroscopy 
Table 1 Investigations for persistent airway eosinophilia

\begin{tabular}{lll}
\hline Clinical measurement & $\mathbf{2 0 0 8}$ & $\mathbf{2 0 1 0}$ \\
\hline Blood eosinophil $\left(\times 10^{9} / \mathrm{L}\right)$ & 4.9 & 5.3 \\
\hline Total serum IgE $(\mathrm{IU} / \mathrm{L})$ & 1500 & 110 \\
\hline ANA, C-, p-ANCA & Not detected & Not detected \\
\hline Aspergillus, farm, bird precipitins & Not detected & Not detected \\
\hline Serum B12, pg/ml & 300 & 258 \\
\hline Serum LDH, IU/L & 124 & 105 \\
\hline Serum tryptase, IU/L & 5 & 3 \\
\hline Serum TARC, pg/ml & Not done & 360 \\
\hline Sputum IL-5, pg/ml & Not done & 220 \\
\hline Stool for parasites $(\times 3)$ & Not detected & Not detected \\
\hline Toxocaris, Strongyloides serology & Negative & Negative \\
\hline Sinus CT & Pan sinusitis & Pan sinusitis, polyps \\
\hline Chest CT & Airspace consolidation & Minimal airspace, no nodes \\
\hline Bone marrow & Normal & No clonal abnormalities \\
\hline T-receptor rearrangements & Not done & Not detected \\
\hline PDGFR-FIP1L1, c-kit, abl-bcr & Not done & Not detected \\
\hline Cardiac MRI & Mild global hypokinesia & Normal, mitral valve prolpase \\
\hline Skin biopsy & Eosinophils, no vasculitis & Not done \\
\hline Colon biopsy & Normal, no vasculitis & Eosinophils, no vasculitis \\
\hline Bronchoscopy & BAL eosinophils $6 \%$ & Not done \\
\hline
\end{tabular}

revealed shallow ulcers in antrum, jejunum, caecum and rectum. Multiple biopsies were taken and HematoxylinEosin (H\&E) stained sections were examined independently by two pathologists who identified only a limited eosinophil infiltration of the gastrointestinal mucosa that was not consider pathological (Figure 1). However, subsequent staining of the same tissue biopsies with $E P X-m A b$ [4] revealed a significant and widespread eosinophilic infiltration that was also accompanied by evidence of marked eosinophil degranulation (i.e., deposition of eosinophil peroxidase within the extracellular matrix (Figure 1). Accordingly, this patient was treated with intravenous corticosteroids with complete resolution of symptoms and improvement of $\mathrm{FEV}_{1}$ to $2.0 \mathrm{~L}$. Subsequently, she was treated with imatinib and later with hydroxyurea, both of which failed to have any prednisone-sparing effect. She declined treatment with interferon-alpha. She is currently on $35 \mathrm{mg}$ daily prednisone in addition to fluticasone+salmeterol 500+50 mcg twice daily, awaiting approval for treatment with mepolizumab, a monoclonal antibody against interleukin 5 (IL-5) [6,7].

\section{Discussion}

This clinical case provides an example of a unique association of eosinophilic gastroenteritis with eosinophilic bronchitis and asthma in the absence of atopy, vasculitis or classical hypereosinophilic syndrome. Our observations with this patient also highlight the utility of a new eosinophil-specific monoclonal antibody as a diagnostic maker of eosinophil-associated disease states.

The three clinical syndromes that may present with symptoms similar to this patient are vasculitis, chronic eosinophilic pneumonia and hypereosinophilic syndrome. Anti-neutrophil antibodies were repeatedly negative and intestinal, sinus and bronchial mucosal tissues did not show evidence of vasculitis. Although the initial radiological feature may have been consistent with chronic eosinophilic pneumonia, subsequent clinical history and radiology were not consistent with this diagnosis. Traditionally, the diagnosis is not entertained in patients who have asthma or chronic rhinosinusitis.. However, it is increasingly recognized that there is considerable overlap between the clinical and molecular patterns observed in patients with eosinophil-mediated diseases [8]. The patient did not have the classic clinical or laboratory features of myeloproliferation. Further, the mutation-related gain-of-function kinase specifically involved in the pathogenesis of myeloproliferative HES (eg, FIP1L1/PDGFRA) was not detected. However, the patient had raised levels of the eosinophilopoietic cytokine IL-5 in sputum (R\&D, Mississauga, ON) and the $\mathrm{T}$-cell derived eosinophilopoietin, TARC, in serum (Calbiochem, Mississauga, ON). However, we were unable to demonstrate $\mathrm{T}$-cell populations in peripheral blood characterized by $\mathrm{TCR} \alpha / \beta-\mathrm{CD} 3-\mathrm{CD} 4+$ or $\mathrm{CD} 3+\mathrm{CD} 4-$ CD8 - that are described in patients with lymphocytic 


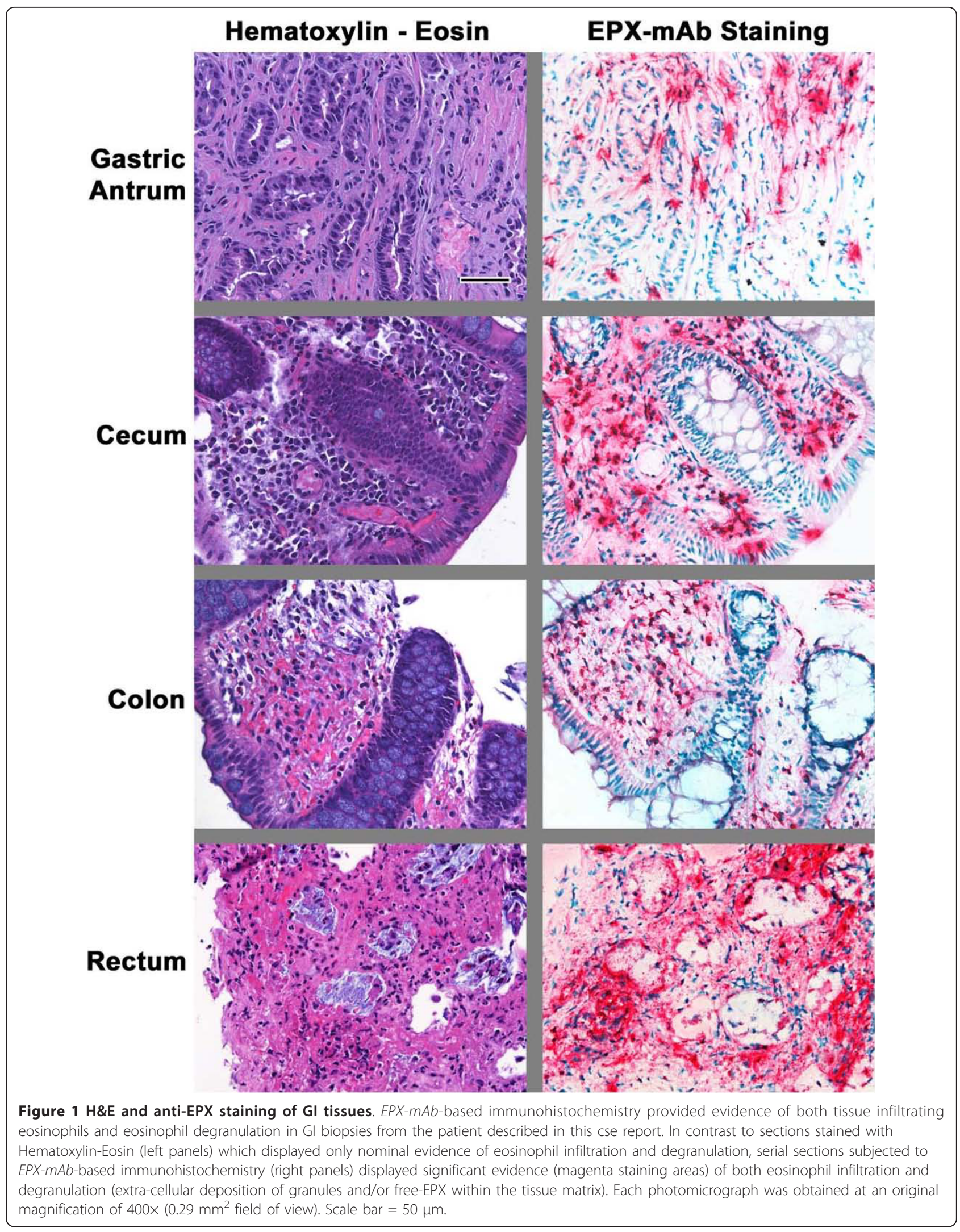


forms of HES [9]. Bone marrow examination did not show any clonal expansion of lymphocytes or eosinophils. Overall, we believe that the patient may have had a variant of a lymphocytic hypereosinophilic syndrome given the systemic eosinophilia, modestly high levels of sputum IL-5 and serum TARC and raised serum total IgE early in the course of the disease. It is possible that an unidentified allergen triggered eosinophil expansion in the bone marrow through an IgE-mediated or a nonIgE-mediated, direct $\mathrm{T}$-cell interaction.

The second novel aspect of this case report is the use of a novel monoclonal antibody to identify eosinophilic infiltration of the gut. The robust character of this novel antibody (specificity and sensitivity) [4] proved invaluable to the establishment of an appropriate diagnosis by detecting both infiltrating eosinophils and the presence of eosinophil degranulation when conventional eosin and hematoxylin staining of the tissue was not interpreted as being significant by two independent pathologists. The other eosinophil granules such as ECP [10] and EDN [11] are not specific to eosinophils, being present on neutrophils. The cationic character of MBP, together with its propensity to "stick" to virtually any substratum as well as its near insolubility in environments at neutral $\mathrm{pH}$ limits its utility for immunohistochemistry [12]. Moreover, these intensely staining local aggregates may give the perception of eosinophil degranulation. In contrast, the nominal cationic character of EPX together with its greater solubility at neutral $\mathrm{pH}$ would prevent aggregation and allow this granule protein to disperse to a greater extent.

The third objective of this case report is to describe our protocol to evaluate patients with asthma who have persistent airway eosinophilia identified as sputum eosinophils $>3 \%$ on two or more occasions (table 1 ). The investigations include workup for atopy, vasculitis, allergic bronchopulmonary aspergillosis, chronic eosinophilic pneumonia and HES. In addition, we also evaluate for hyperplastic chronic rhinosinusitis and non-IgE mediated eosinophilia possibly mediated by antigen-triggered IL-5 release from T-lymphocytes. We also recommend an assessment of steroid pharmacokinetics to monitor compliance and gastrointestinal absorption of ingested corticosteroids.

In summary, this case describes a patient who likely has a lymphocytic variant of hypereosinophilic syndrome that resulted in eosinophilic infiltration of the gastrointestinal tract, sinuses, and airway that contributed to variable airflow obstruction. The case history also illustrates the diagnostic workup of a patient with asthma who has a prednisone-dependent airway eosinophilia. The use of a novel $E P X-m A b$ provided a reliable method to identify eosinophils in the gastrointestinal tract. Further research is necessary to identify the triggers for eosinophilia in L-HES and the application of the novel monoclonal antibody directed against eosinophil peroxidase to detect eosinophil activity in the airway.

\section{Consent}

Written informed consent was obtained from the patient for publication of this case report and accompanying images. A copy of the written consent is available for review by the Editor-in-Chief of this journal.

\section{Acknowledgements}

We acknowledge the help of Dr Mike Trus, Dr Susan Waserman, Dr Nader Khalidi, Dr Robert Spaziani and Dr Mark Larche in the management of this patient. Dr Nair is supported by a Canada Research Chair in Airway Inflammometry, Drs. N Lee and J Lee are supported by grants from the NIH (NAL: HL058732 and JJL: HL065228, RR019709).

\section{Author details}

${ }^{1}$ Firestone Institute for Respiratory Health, St. Joseph's Healthcare and Department of Medicine, McMaster University, Hamilton, Ontario, Canada. 2Division of Pulmonary Medicine, Mayo Clinic, Scottsdale, AZ, USA.

\section{Authors' contributions}

PN conceived the report and provided clinical care, JL, NL, CP and SO performed all the immunohistochemistry, ES assisted with the

immunological measurements. All authors have read and approved the manuscript.

\section{Competing interests}

The authors declare that they have no competing interests.

Received: 9 January 2011 Accepted: 1 March 2011

Published: 1 March 2011

\section{References}

1. Furuta GT, Forbes D, Boey C, Dupont C, Putnam P, Roy S, Sabra A Salvatierra A, Yamashiro Y, Husby S, Eosinophilic Gastrointestinal Diseases Working Group: Eosinophilic gastrointestinal diseases (EGIDs). J Pediatr Gastroenterol Nutr 2008, 47:234-8.

2. Blanchard C, Wang N, Rothenberg ME: Eosinophilic esophagitis: pathogenesis, genetics, and therapy. J Allergy Clin Immunol 2006, 118:1054-9.

3. Roufosse F: Hypereosinophilic syndrome variants: diagnostic and therapeutic considerations. Haematologica 2009, 94:1188-93.

4. Protheroe C, Woodruff SA, de Petris G, et al: A novel histologic scoring system to evaluate mucosal biopsies from patients with eosinophilic esophagitis. Clin Gastroenterol Hepatol 2009, 7:749-755, e11.

5. Pizzichini E, Pizzichini MM, Efthimiadis A, Hargreave FE, Dolovich J: Measurement of inflammatory indices in induced sputum: effects of selection of sputum to minimize salivary contamination. Eur Respir J 1996, 9:1174-80.

6. Roufosse F, de Lavareille A, Schandené L, et al: Mepolizumab as a corticosteroid-sparing agent in lymphocytic variant hypereosinophilic syndrome. J Allergy Clin Immunol 2010, 126:828-835, e3.

7. Nair P, Pizzichini MM, Kjarsgaard M, et al: Mepolizumab for prednisonedependent asthma with sputum eosinophilia. N Engl J Med 2009, 360:985-93.

8. Simon HU, Rothenberg ME, Bochner $B S$, et al: Refining the definition of hypereosinophilic syndrome. J Allergy Clin Immunol 2010, 126:45-9.

9. Ravoet M, Sibille C, Gu C, et al: Molecular profiling of CD3-CD4+ T cells from patients with the lymphocytic variant of hypereosinophilic syndrome reveals targeting of growth control pathways. Blood 2009, 114:2969-83.

10. Sur S, Glitz DG, Kita H, et al: Localization of eosinophil-derived neurotoxin and eosinophil cationic protein in neutrophilic leukocytes. J Leukoc Biol 1998, 63:715-722.

11. Leigh R, Belda J, Kelly MM, et al: Eosinophil cationic protein relates to sputum neutrophil counts in healthy subjects. J Allergy Clin Immunol 2000, 106:593-4 
12. Kato $M$, Kephart $G M$, Talley NJ, et al: Eosinophil infiltration and degranulation in normal human tissue. Anat Rec 1998, 252:418-425.

doi:10.1186/1710-1492-7-4

Cite this article as: Nair et al:: The identification of eosinophilic gastroenteritis in prednisone-dependent eosinophilic bronchitis and asthma. Allergy, Asthma \& Clinical Immunology 2011 7:4.

Submit your next manuscript to BioMed Central and take full advantage of:

- Convenient online submission

- Thorough peer review

- No space constraints or color figure charges

- Immediate publication on acceptance

- Inclusion in PubMed, CAS, Scopus and Google Scholar

- Research which is freely available for redistribution

Submit your manuscript at www.biomedcentral.com/submit
Ciomed Central 